\title{
Alternative Energy - Environment Safety
}

\author{
Sefer Kurnaz* \\ The Aeronautics and Space Technologies Institute Air Force Academy, \\ Istanbul, Turkey,
}

Rustam B. Rustamov**

Institute of Physics Azerbaijan National Academy of Sciences, Baku, Azerbaijan, Ismayil Zeynalov ***

Institute of Ecology, Azerbaijan National Aerospace Agency, Baku, Azerbaijan

\begin{abstract}
It is undertaken systematization of results of satellite and ground observation parameters characterizing a current condition and climatic variability of two selected geographical areas. One of them covers territory of Azerbaijan and another covers a wide area of Caspian See region. Average values and mean square deviations of following values are investigated: outgoing long wave radiation during a day and night (in nebulosity and cloudless), absorbed within a day of the stream of a sunlight of the system in "a terrestrial surface-atmosphere", degree of a covering by clouds of the selected areas during a day and at night, ground temperature values of air, pressure and speed of a wind. Monthly average values of corresponding parameters create a basis of suggested investigations. It has been presented features of a time course of investigated parameters for each month and year in the whole due to the continuously observations since 1982-2000.

The scientific problem consists that there are no existed models which authentically would be cover the main aspects of a realities specified changes: they are identified by economic activities, growth of the population and other features of development of a human society or internal fluctuations of biogeophysical/climatic system. Possibilities of predictability of biosphere and climate changes depend on available timely supervision, adequacy of construction of appropriate models, understanding of mechanisms of direct and feedback influences in such complicated systems.
\end{abstract}

Keywords : Wavelength, radiation, environment, monitoring, hydro meteorological network station, NOAA satellite data

\section{Introduction}

The process of globalization demands the use of alternative energy sources that in many cases plays as the factor of the environmental and ecological safety issues. It is necessary to note that the use of the traditional energy sources have a highly negative

\footnotetext{
* Director

** Coordinator

E-mail :r_rustamov@hotmail.com Tel : (+99450)3668949 Fax : (+99412)4929889

*** Senior Scientist
} 
impact to the environment. An indicated environmental issue can not be take objective character due to the insufficient information on traditional sources of environmental contamination.

In the initial stage this problem can be identified with the finding out a more adequate and economical energy sources. For this reason there is a requirement of definition of raw material for using as a possible good for alternative energy source. And second approach is to consider technology of processing of energy supply.

Obviously a greater and long-term of energy source is Sun. Presently exploration on utilization of the alternative sources of energy bases on conversion of the sunlight to electrical or thermal energy. Investigation of solar days in the territory of Azerbaijan will allow of making appropriate decision for further alternative energy applications. Profusion of sunlight and heat energy are different in the foothill parts of country in particular in the area of Araz river of the Autonomic Republic Nakhchivan, Absheron peninsula, in the Kur and Araz lowland, Ganja-Kazakh inclined plain, Alazan-Agrichay valley and Samur Devechi lowland.

A rich sunlight and heat energy inflow has a case in Araz zone of the Nakhichevan Autonomous Republic, having about 28002500 hours. On Absheron peninsula, Kur Araz lowland, Ganja - Kazakh inclined plain, Alazan - Agricay valley the duration of sunlight is a comparatively less than 2500 - 2200 hours. In average annual and high-mountainous zones of the Big and Small Caucasus as well as in Lenkoran district make areas basically 2200 - 1900 hours. Consequently in spite of the complexity of surface, number of sunlight hours it is enough considerably and fluctuate for a year from 2800 up to 1900 hours [1] .

Taking into account a special place of satellite observation for understanding of trends occurring in the global changes there is a necessity of development of a new model for estimation of condition parameters of biosphere (such, as wood volume green biomass and grassy vegetation). On place of the traditional concept of "vegetative indexes " - some combinations of measuring channels of scanning satellite radiometers more modern models of an estimation of parameters applying of development of a new approache on studying of the global biogeochemical cycles. Satellite observation brings a significant contribution on understanding of global ecological problems, defining prospects of realization of geoinformation models of estimation of condition parameters of biosphere for the considered purposes instead of traditional use of number of models. In this case essential place has an availability of systematized satellite and ground supervision data (accessible, in particular, through an Internet network) with characteristics defining a current condition of biosphere and climate. This data should promote the enhancement of mentioned above models of predictability of observable changes [2].

\section{Initial Data Access}

The main systematized data of the ground hydrometeorological network stations and satellite supervision for the whole of globe can be received by using the server network of the USA National Ocean and Atmosphere Administration (NOAA). There is a separate entity of NOAA Satellites and Information with the body of the National Environmental Satellite, Data and Information Service (NESDIS). Within the framework of the NESDIS is functioning the Office of Satellite Data Processing and Distribution (OSDPD) for processing and distribution of satellite data which provides processing, systematization and supply to users in the USA and other countries data and information from the environmental satellites. The final goal of user' $s$ maintenance is reaching by appropriate information production over the following three institutions: Satellite Services Division (SSD); Information Processing Division (IPD); Direct Services Division (DSD). 
There are number of other institutions for maintenance of the initial data for monitoring of the environment.

For the considered purposes in the paper has been used the data from the IPD divisions of the Satellite Active Archive (SAA) through the Internet network. In the network is presented an opportunity of selection of such information which refers to Advanced Very High Resolution Radiometer (AVHRR); Pathfinder - specialized software. Information production of the AVHRRPF (sometimes calls as PATMOS) with a free of access represents of the number of USA satellites NOOA-7-9- and 14 .

Within the framework of the PATMOS-A1 statistical characteristics have been calculated using the indicated above satellites for intensive outgoing radiation in all five channels: two channels of visible area of the spectrum, two channels as called "atmosphere transparency windows" for 10-12 micrometers and near infrared area for elimination of impact of atmospheric cloudless and cloudy conditions. Cloudy cover statistical characteristics have been calculated where condition describes by a huge of parameters. Based on the PATMOS-A2 version statistical characteristics of the atmospheric aerosol optical thickness above oceans as well as values of the absorbed solar (short wavelength) radiation and thermal (long wavelength) radiation have been calculated which define radiation balance on the top of an atmosphere. In the climate and climate changes investigations usually use a monthly average values of appropriate characteristics.

Below presents some of data analysis results of the PATMOS-A2 information production for the term of $1982-2000$ in two allocated areas of Near-Caspian region (from 380 up to 420 north longitude, from 440 to 520 east latitude; and from 340 up to 500 north longitude, from 440 up to 560 east latitude) incorporation with data of a ground measuring network based on characteristics, as monthly average values of air temperature, atmospheric pressure and average speed of a wind at the surface level. The first of selected areas approximately covers the territory of Azerbaijan and second - wider area of territory of Russia, Azerbaijan, Georgia, Iran, Turkmenistan and Kazakhstan. The specified data of a ground network are accessible through the Internet network and other information centre of the USA National Climate Data Center (NCDC).

It can be considered some of examples of interpretation to be received information production for the purposes of investigation of climate variability of selected two foregoing mentioned Near-Caspian region for the last 20 years [3, 4].

\section{The Problem Search Approach}

In Fig. 1 and 2 have been presented results of monthly average values of long wavelength radiation at the top atmosphere level in the daylight (Fig. 1) and at night (Fig. 2) and also mean square deviations for the chosen 19 years based on the continuously supervision (from January 1982 up to December 2000) for two selected regions. At the same time in the bottom part of Fig.1 and 2 corresponding to the mid-annual values (averaging for 12 months) and their mean square deviations for each year considered supervision is presented. There is a sufficient smooth course of monthly average values for both selected districts with maxima in July-August and much more complex time course corresponding mean square deviations (the top curves Fig.1 and 2) with strongly pronounced maxima in November and February and on the contrary, minima in July-August. Monthly average values of appropriate values change approximately from $200 \mathrm{~W} / \mathrm{m} 2$ up to $250 \mathrm{~W} / \mathrm{m} 2$ (the left scale), them mean square deviations - from $3 \mathrm{~W} / \mathrm{m} 2$ up to $8 \mathrm{~W} / \mathrm{m} 2$. The presence of those smooth curves for monthly average values reflect the temperature timing code of system "terrestrial surface-atmosphere" during a day and night time consequently and their course mean square deviations reflect a variability of influence of cloudy systems during fixed time of a day in the mentioned regions. 
A significant complexity is the behavior of mid-annual values of investigated value and those mean square deviations for every year from the selected 19 years observation. It can be indicated practically regular deviation in mid-annual values of passed long wavelength radiation within a day of two selected regions. For example on the bottom curves of Fig. 1 these values were as $237 \mathrm{~W} / \mathrm{m} 2$ in 1982 and $244 \mathrm{Vt} / \mathrm{m} 2$ for the selected "square" of Azerbaijan territory and all the Caspian region, consequently: $246 \mathrm{~W} / \mathrm{m} 2$ and $252 \mathrm{~W} / \mathrm{m} 2$ in 1989; $233 \mathrm{~W} / \mathrm{m} 2$ and $237 \mathrm{~W} / \mathrm{m} 2$ in 1993 (the minimal values of all considered period of observations); $248 \mathrm{~W} / \mathrm{m} 2$ and $257 \mathrm{~W} / \mathrm{m} 2$ in 1995 (the maximal values for all considered period). The bottom curves of the Fig. 2 (at night) do not show such significant divergences for mid-annual values of corresponding values, showing nevertheless obvious similarity in extreme events 1989, 1993, 1995 and other years of observation with data Fig. 1 (day time). These divergences are possible to explain more complexity character of influence of cloudy systems in the daylight to the final values of investigated mid-annual values for the selected regions, than at night. Any other explanations of these divergences would also be possible.

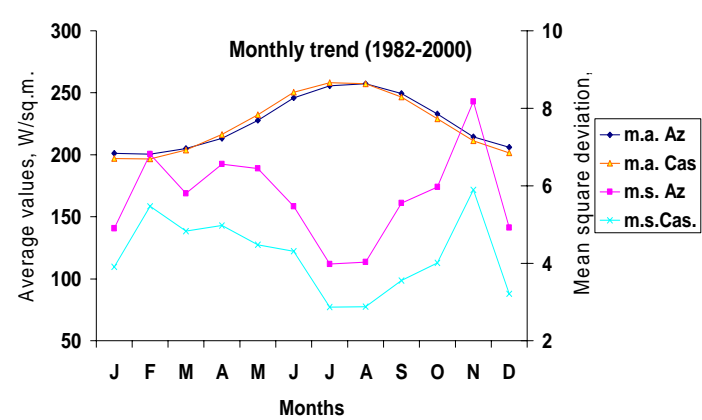

a)

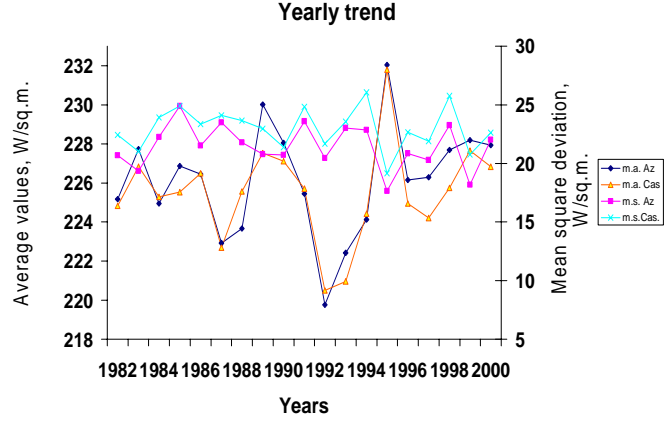

b)

Fig. 1. Outgoing long wave radiation in the daylight: a) - monthly trend, b) - year trend

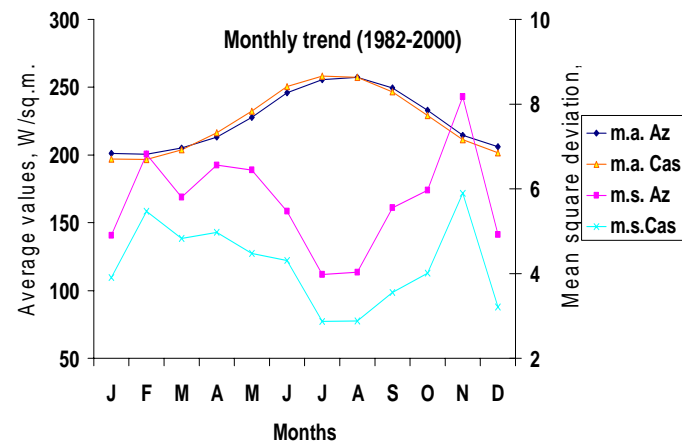

a)

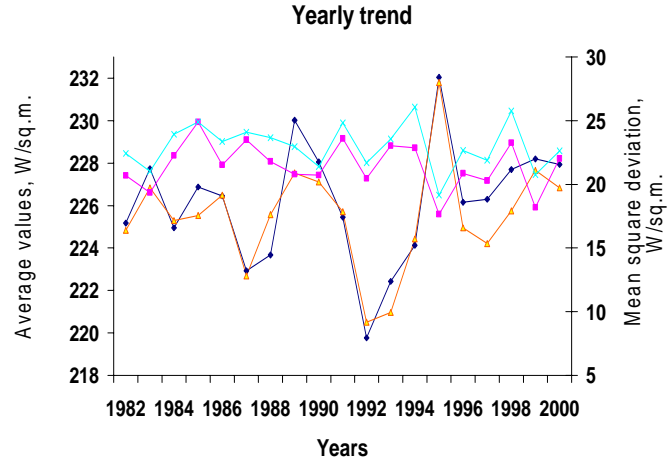

b)

Fig. 2. Outgoing long wave radiation at night: a) - monthly trend, b) - year trend 


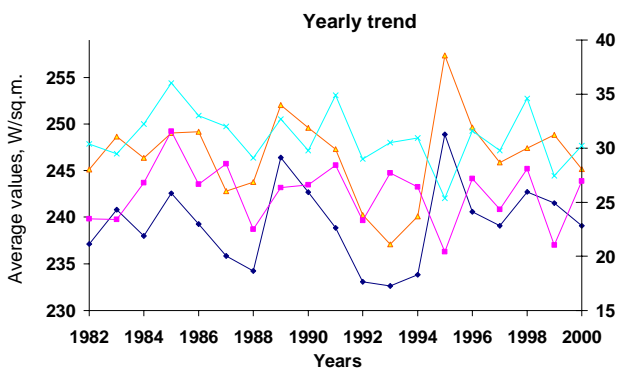

a)

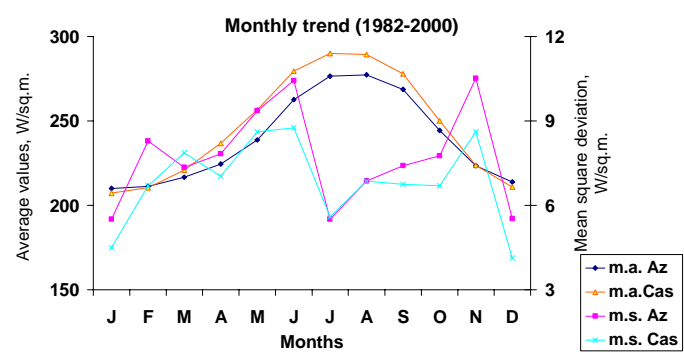

b)

Fig. 3. Outgoing long wave radiation for the not cloud sky in the daylight: a) - monthly trend, b) - year trend

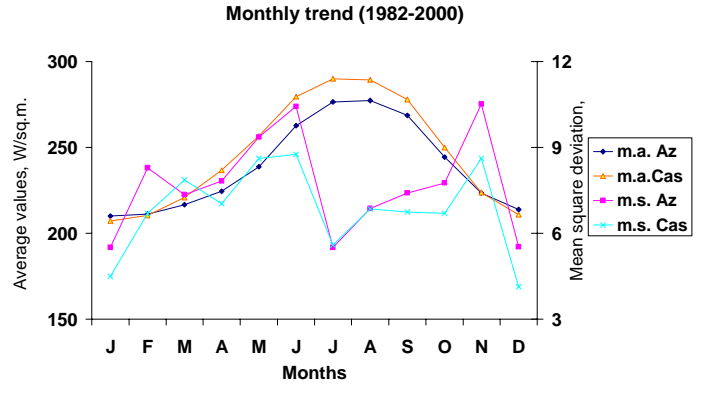

a)

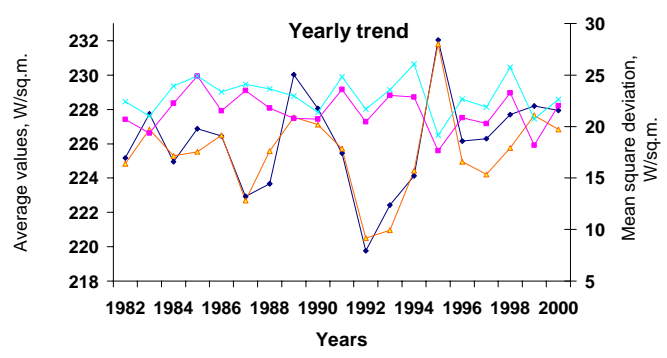

b)

Fig. 4. Outgoing long wave radiation for the not cloud sky at night:

a) - monthly trend, b) - year trend

Concerning the behavior of the mean square deviations of passed long-wavelength radiation (the lower curves in Fig.1 and Fig. 2) the maxima and minima for selected "squares" are appreciable. For example on the lower curves in 1982 corresponding values have made 24 $\mathrm{W} / \mathrm{m} 2$ and $31 \mathrm{~W} / \mathrm{m} 2$; in $1985-31 \mathrm{~W} / \mathrm{m} 2$ and $36 \mathrm{~W} / \mathrm{m} 2$ (the maximal values for all considered period); in $1995-20 \mathrm{~W} / \mathrm{m} 2$ and $26 \mathrm{~W} / \mathrm{m} 2$ (the minimal values for all considered period), etc. It is possible to conclude that the similar conditions for the previous average values at night, in the part of more rapprochements of curves for both regions and in mean-square deviations for these conditions. But those rapprochements are not so appreciable.

Based on the analysis of data indicated in Fig.1 and Fig. 2 is possible to be convinced that the extreme from the point of view of variability of mid-annual temperature of territories observable from satellites are 1993 and 1995 and from the point of view of mean-square deviations of this value - 1985 and the same 1995. The received results demand the further investigations.

In Fig. 3 and Fig. 4 have been performed the similar results which characterize the thermal features of territories observable from satellites in case of the "at the cloudless sky". The fact is that within the selected days it is possible to accept information for the same territories from the several NOAA satellites (in a reality up to four coils from two simultaneously functioning satellites). Appropriate territories can be covered during separate coils by overcast or to be independent in operation. During the presentation of the final information production in the form of monthly average values a part of corresponding stages inevitably "presence" of a cloudy cover and other part of piece might be not to contain of clouds. Summarized characteristics of cloudy-cloudless system have been presented in Fig. 1 and Fig. 2 and cloudless conditions have been presented by curves Fig. 3 and Fig. 4. 
It is possible to be convinced that monthly average values of passed long-wavelength radiation at the cloudless sky (the top graph) within the sunlight day (Fig. 3) and at night (Fig. 4) for selected months has a small differences from the similar curves indicated in Fig. 1 and Fig. 2. There is no a significant differences and the similar curves for meansquare deviations of corresponding values (maximal deviations in October-November, minimal - in July-August). Divergences in behavior of the lower curves in Fig. 3 and Fig. 1 are much more significant. For example, behavior of mid-annual values illustrated in Fig. 3 values is actually abnormal in comparison with Fig.1: in 1984 the minimal values equal 248 $\mathrm{W} / \mathrm{m} 2$ and $271 \mathrm{~W} / \mathrm{m} 2$ (for the "square" covering territory of Azerbaijan and wider Caspian region, accordingly) were recorded; in 1995 the maximal values of measured characteristics of system were the same $(279 \mathrm{~W} / \mathrm{m} 2$ and $286 \mathrm{~W} / \mathrm{m} 2$, accordingly), but their absolute values have been appeared almost $30 \mathrm{~W} / \mathrm{m} 2$ more than in case of Fig. 1.

It can be indicated that the mean-square deviations illustrated in Fig. 3 values have a different behavior then it has mentioned in Fig. 1. For example, the maximum of these deviations for territory of Azerbaijan (absolute value is about $52 \mathrm{~W} / \mathrm{m} 2$ ) with subsequent equal enough course of corresponding values about $20 \mathrm{~W} / \mathrm{m} 2$ for other years of observation is again observable. Occurrence of a maximum of these deviations for Caspian region (its absolute value reaches $80 \mathrm{~W} / \mathrm{m} 2$ ) is even more unexpected at subsequent smooth enough course close $30 \mathrm{~W} / \mathrm{m} 2$ for other years of observation. Probably not clear issues are connected with a small volume of selective data on cloudless conditions in considered regions. On the other hand, curves of mid-annual values of Fig. 4 (the lower curves) are almost the same for the similar curves in Fig. 2. But there are differences on absolute values (240-250 W/m2 in Fig.4 against 220-230 W/m2 in Fig. 2). Taking the base of absolute values differ the mean-square deviations of illustrated values of passed long-wavelength radiation at night at the cloudless sky in comparison with the general situation (these values are at the level $15-20 \mathrm{~W} / \mathrm{m} 2$ for data Fig. 4 against $20-25 \mathrm{~W} / \mathrm{m} 2$ for data Fig. 2).

The conducted analysis of available archives of satellite data and earth ground observations for two selected regions covering Caspian Sea and states within Caspian region has shown prominent features of annual average and interannual values of appropriate values as well as mean square deviations of these values from their average values during 19 years observation (1982 - 2000). The received results have shown the certain regularity in behavior of investigated values and to clarify some of results on interpretation of data. These are the first results of such investigations of the general set of the parameters describing a condition and variability of biosphere and a climate of selected regions. A basis of the further investigations in this direction should become studying of criteria of the statistical importance of the received results.

These graphs can reflect the general picture on change of components of radio balance of surface. An uncontested output for reducing of climatic change negatives is a use of alternative energy sources.

A more realistic definition of power sources can be undertaken by restriction of an estimation of power reserves only for available energy sources.

Considering a degree of influence to the environment of the renewed energy sources during operation it can be considered as well as economical aspects of the mentioned issue. 


\section{Conclusion}

The nagging problem being today due to the exhaustion of the hydrocarbon fuel and pure air demands of goals and tasks on discovering of the alternative energy sources and their storage. Present status of use of the hydrocarbon energy sources are the reason of numerical global problems.

Using the software developed for forecasting of climatic characteristics based on use of satellite and ground meteorological data is possible to develop and apply of nonstationary technologies of electric power produce.

Considering extensiveness of investigations there is a possible determination of the optimal location for receiving of the climatic analysis standard. Using the climatic characteristics data of territory of Azerbaijan Republic, considering it 9 climatic zones from available 12 is possible to predict their changes.

Received results demonstrate availability of use of presented data collection and data processing method and technology for development of location of technologies on alternative energy sources supply. Moreover, presented arguments testify prospects and advantages of use of Azerbaijan territory as a testing area for carrying out of investigations.

\section{References}

1. E.M. Shihlinsky "Thermal balance of Azerbaijan USSR" Publishing house "Elm", 1969 p. 10

2. V.V. Kozoderov, B.S. Kosolapov “A New approaches of the inverse task solving of the restoration of the green fitomass volume of the forest vegetation based on aerospace data”, Journal of Earth Research from Space, 1999, N 1, p. 28-36

3. V.V. Kozoderov, V.V.Titov, I.M. Zeynalov, "Changes of biosphere and a climate: a role of satellite and ground supervision". World. konf. On change of a climate, 2003. p. 300305

4. The project UNESCO/Keizo OBUCHI Fellowships on "The influence of Natural and Anthropogenic Factors on Changeability of Climate Characteristics of Azerbaijan Territory and Water Area of the Caspian Sea" 2002. 